Article

\title{
Surface Modification of Curcumin Microemulsions by Coupling of KLVFF Peptide: A Prototype for Targeted Bifunctional Microemulsions
}

\author{
Rungsinee Phongpradist ${ }^{1,2}$, Wisanu Thongchai ${ }^{3}$, Kriangkrai Thongkorn ${ }^{4}\left(\mathbb{D}\right.$, Suree Lekawanvijit ${ }^{5}$ \\ and Chuda Chittasupho ${ }^{1, *(D)}$
}

1 Department of Pharmaceutical Sciences, Faculty of Pharmacy, Chiang Mai University, Chiang Mai 50200, Thailand; rungsinee.p@cmu.ac.th

2 Center of Excellence for Innovation in Analytical Science and Technology for Biodiversity-Based Economic and Society (I-ANALY-S-T_B.BES-CMU), Chiang Mai University, Chiang Mai 50200, Thailand

3 Chemistry Program, Faculty of Science and Technology, Pibulsongkram Rajabhat University, Phitsanuloke 65000, Thailand; wisanuthongchai@psru.ac.th

4 Department of Companion Animals and Wildlife Clinic, Faculty of Veterinary Medicine, Chiang Mai University, Chiang Mai 50100, Thailand; kriangkrai.th@cmu.ac.th

5 Department of Pathology, Faculty of Medicine, Chiang Mai University, Chiang Mai 50200, Thailand; suree.lek@cmu.ac.th

* Correspondence: chuda.c@cmu.ac.th

\section{check for}

updates

Citation: Phongpradist, R.;

Thongchai, W.; Thongkorn, K.;

Lekawanvijit, S.; Chittasupho, C. Surface Modification of Curcumin Microemulsions by Coupling of KLVFF Peptide: A Prototype for Targeted Bifunctional Microemulsions. Polymers 2022, 14, 443. https://doi.org/ $10.3390 /$ polym 14030443

Academic Editors: Lee Eun Je and Naved Azum

Received: 14 December 2021

Accepted: 19 January 2022

Published: 22 January 2022

Publisher's Note: MDPI stays neutral with regard to jurisdictional claims in published maps and institutional affiliations.

Copyright: (C) 2022 by the authors. Licensee MDPI, Basel, Switzerland. This article is an open access article distributed under the terms and conditions of the Creative Commons Attribution (CC BY) license (https:// creativecommons.org/licenses/by/ $4.0 /)$

\begin{abstract}
Curcumin is one of the most promising natural therapeutics for use against Alzheimer's disease. The major limitations of curcumin are its low oral bioavailability and difficulty in permeating the blood-brain barrier. Therefore, designing a delivery system of curcumin to overcome its limitations must be employed. KLVFF, a peptide known as an amyloid blocker, was used in this study as a targeting moiety to develop a targeted drug delivery system. A prototype of transnasal KLVFF conjugated microemulsions containing curcumin (KLVFF-Cur-ME) for the nose-to-brain delivery was fabricated. The KLVFF-Cur-ME was developed by a titration method. A conjugation of KLVFF was performed through a carbodiimide reaction, and the conjugation efficiency was confirmed by FTIR and DSC technique. KLVFD-Cur-ME was characterized for the drug content, globule size, zeta potential, and $\mathrm{pH}$. A transparent and homogeneous KLVFF-Cur-ME is achieved with a drug content of $80.25 \%$ and a globule size of $76.1 \pm 2.5 \mathrm{~nm}$. The $\mathrm{pH}$ of KLVFF-Cur-ME is $5.33 \pm 0.02$, indicating non-irritation to nasal tissues. KLVFD-Cur-ME does not show nasal ciliotoxicity. An ex vivo diffusion study revealed that KLVFF-Cur-ME partitions the porcine nasal mucosa through diffusion, following the Higuchi model. This investigation demonstrates the successful synthesis of a bifunctional KLVFF-Cur-ME as a novel prototype to deliver anti-A $\beta$ aggregation via an intranasal administration.
\end{abstract}

Keywords: microemulsions; modified Pluronic; targeted; surface modification; KLVFF; curcumin

\section{Introduction}

Alzheimer's disease (AD) contributes to $60-70 \%$ of dementia cases, mostly found in the elderly [1]. At present, the pathophysiology of Alzheimer's disease is still not clear, but the beta-amyloid plaque $(\mathrm{A} \beta)$ is one of the pathological hallmarks, and is considered a target for treatment. Current therapeutic agents, which are available to treat AD, fall into two categories, including drugs that only treat cognitive symptoms and drugs that may delay clinical decline by removing $\mathrm{A} \beta$ [2]. Most therapeutic agents are in the form of tablets and capsules, which cause issues for patients in late-stage AD with swallowing difficulties [3]. These reasons led to the development of various drug formulations administered through routes other than oral. The delivery of the drugs directly to the brain has been shown to improve the efficacy of the treatment [4]. Nowadays, the intranasal administration (IN) of drugs has gained attention because of several advantages, including the direct access of 
drugs from the nasal cavity to the central nervous system, non-invasive administration, convenience for self-medication, and improved patient compliance [5,6]. In addition, intranasal to brain delivery can also avoid the blood-brain barrier and hepatic firss-pass metabolism, which are the main obstacles of oral drug delivery $[7,8]$. Notwithstanding, intranasal drug delivery encounters the restriction of a poor drug diffusion through the nasal mucosa, leading to an insufficient concentration of drug delivery to the desired target site and, thus, the therapeutic effect cannot be achieved [6].

Nanosize drug delivery systems provide an improved delivery from the nose to the brain because they can enhance a drug's solubility, permeability, and help protect the encapsulated drugs from chemical and physical degradation [8-10]. In addition, nanoscale drug delivery systems, particularly through passive targeting, have been hypothesized to allow the drugs to reach the target tissue and release the active drugs [11]. Over past decades, microemulsions (ME) has also attracted much interest as a drug delivery system and it has been reported as a suitable carrier of drugs for solving the solubility problem [5,12]. ME consists of an aqueous phase, an oil phase, and a mixture of a surfactant and co-surfactant [13]. In general, ME is a transparent, optically isotropic, and thermodynamically stable system [14]. ME provides definite advantages, including thermodynamic stability, a high solubilizing capacity for the lipophilic drugs, enhancing permeability through the biological membranes, increasing bioavailability, and reducing the inter-and intra-individual variability in drug pharmacokinetics [5,12]. Numerous studies have shown that microemulsions can be effectively applied as drug carriers for several routes of administration, including intranasal administration [5,13,15-17]. Microemulsions of carbamazepine and rivastigmine have shown to increase the intranasal uptake of drugs into the brain $[5,15,18]$.

The transportation of drugs directly to the targeted pathophysiology of the disease is the goal of the treatment, because targeted therapy raises the therapeutic effects while minimizing undesired effects of drugs on the untargeted sites. Surface-modified nanocarriers can be delivered to the target site, such as the CNS, through a conjugation of the targeting moiety, which is the ligand for specific proteins that specifically present in the pathophysiology of the disease $[9,19]$. Many researchers have investigated the targeting delivery for CNS treatment, including the surface modification of the nanocarrier [20-24]. However, to our knowledge, surface-modified microemulsions for nasal-to-brain targeting drug delivery have not been reported previously; hence, the development of this system would provide a promising novel strategy for intranasal administration. One of the pathological hallmarks of $\mathrm{AD}$ is $\mathrm{A} \beta$ aggregation [25]. Thus, a molecular modulator that is specific to $\mathrm{A} \beta$ aggregation could be used as a targeting moiety to prevent and treat $\mathrm{AD}$, specifically. Interestingly, the KLVFF peptide was reported as an inhibitor of $A \beta$ aggregation $[26,27]$. KLVFF was first synthesized by Tjernberg et al. [28]. It is a peptide sequence containing 16-20 residues, designed from the full-length peptide, which hinders A $\beta$ fibrillogenesis, resulting in the inhibition of amyloid aggregation [28,29]. KLVFF contains a diphenylalanine sequence, which plays a significant role in amyloid aggregation by forming highly extended fibrils with a $\beta$-sheet structure [30]. KLVFF could bind the confined region of the $\mathrm{A} \beta$ strand and interfere with the attachment of neighboring $\mathrm{A} \beta$ strands for assembly and aggregation [27]. Thereafter, KLVFF was grafted with drug carriers for $\mathrm{A} \beta$ plague targeting [31].

Curcumin, a phenolic compound, is a low-molecular-weight molecule derived from the rhizome of Curcuma longa L., a member of the Zingiberaceae family [32-34]. Several pharmacological activities of curcumin have been reviewed, including its antioxidant, antimicrobial, antitumor, and anti-inflammation capabilities [32,33]. Strong evidence indicated a neuroprotective action of curcumin against $\mathrm{AD}[34,35]$. Curcumin demonstrated the strongest inhibitory effect in preventing fibril formation among 214 antioxidant compounds [36]. It is known as a potent inhibitor of $A \beta$ aggregation [37]. Curcumin has been reported to reduce the $\beta$-sheet content of the peptide, destabilize and disaggregate $\mathrm{A} \beta$ fibrils, decrease the toxicity of $\mathrm{A} \beta$ oligomers, and reduce amyloid formation in vivo $[34,37,38]$. However, the obstacles of curcumin being used for clinical applications 
are its low hydrophilicity, rapid metabolization, poor absorption, low bioavailability, low permeability, and lack of targeting capabilities [34,39]. Hence, drug delivery systems are addressed to overcome such drawbacks to improve the biological and pharmacological activity of curcumin.

The strategy for this study is to combine the merits of targeted drug delivery systems with the transnasal route of administration. We propose that binary inhibitors (curcumin and KLVFF) of amyloid aggregation, which have different binding sites, would additively or synergistically inhibit $\mathrm{A} \beta$ aggregation. This study describes the synthesis and characterization of surface-modified microemulsions encapsulating curcumin. In addition, the microemulsions containing curcumin are coupled with the KLVFF peptide for specific binding to $\mathrm{A} \beta$ fibrils. A bifunctional microemulsions was hypothesized to have dual modes of action, i.e., the $\mathrm{A} \beta$ aggregation inhibition of curcumin and KLVFF, and the targeting delivery property of the KLVFF peptide. The physicochemical properties, a chemical analysis, and nasal ciliotoxicity study were investigated to confirm the possibility of curcumin microemulsions conjugated using the KLVFF peptide as a prototype for bifunctional microemulsions for the treatment of AD via the intranasal route.

\section{Materials and Methods}

\subsection{Experimental Materials}

Pluronic F-127 ${ }^{\circledR}$ was a gift from BASF chemical company (St. Louis, MO, USA). 1-Ethyl3-[3-dimethylaminopropyl]-carbodiimide hydrochloride (EDC), N-hydroxysulfosuccinimide (sulfo-NHS), tetrahydrofuran (THF), dimethylaminopyridine (DMAP) succinic anhydride polysorbate 80 (TWEEN 80), Sorbitan monolaurate (Span 20), glycerine, propylene glycol, polyethylene glycol 400 (PEG 400), and isopropyl myristate (IPM) were purchased from Sigma-Aldrich (St. Louis, MO, USA). Ethanol, methanol, and carbon tetrachloride were obtained from Sigma-Aldrich (Steinheim, Germany). Curcumin was obtained from Merck (Darmstadt, Germany). KLVFF peptide was synthesized and purified by PEPMIC (Suzhou, China). Monobasic potassium phosphate was purchased from RCI Labscan (Bangkok, Thailand). Sodium hydroxide was obtained from KEMAUS (New South Wales, Australia).

\subsection{Synthesis of Carboxylated Pluronic (COOH-Pluronic F127)}

Terminal hydroxyl groups on Pluronic F127 ${ }^{\circledR}$ were converted to carboxyl groups according to the following procedure. Pluronic $\mathrm{F} 127^{\circledR}$ was dissolved in tetrahydrofuran (THF, $60 \mathrm{~mL}$ ). Then, 4-dimethylaminopyridine (DMAP, $98 \mathrm{mg})$, triethylamine $(108 \mu \mathrm{L})$, and succinic anhydride $(800 \mathrm{mg}$ ) were added. The mixture was stirred for $48 \mathrm{~h}$ at room temperature. The solution was dried by rotary evaporation and was dissolved in carbon tetrachloride $(30 \mathrm{~mL})$. The excess succinic anhydride was removed by filtration. The $\mathrm{COOH}-$ Pluronic F127 was purified by precipitation with ice-cold diethyl ether. The product was identified by FTIR spectroscopy. The illustration of synthetic route of carboxylated Pluronic F127 is shown in Figure 1A.

\subsection{Synthesis of KLVFF Conjugated COOH-Pluronic F127 (KLVFF-Pluronic F127)}

Carboxylated Pluronic was conjugated to the amino groups of KLVFF peptide by a carbodiimide reaction which is mainly used to form amide linkages between amines and carboxylates $[40,41]$. The Pluronic-COOH was dissolved in deionized water and was allowed to react with 1-ethyl-3-[3-dimethylaminopropyl] carbodiimide hydrochloride (EDC) and sulfo-NHS for $1 \mathrm{~h}$. KLVFF peptide was added to the activated COOH-Pluronic F127 and stirred for $16 \mathrm{~h}$ at room temperature. The KLVFF peptide conjugated $\mathrm{COOH}-$ Pluronic F127 (KLVFF-Pluronic F-127) was dialyzed against deionized water for $16 \mathrm{~h}$ to remove excess of uncoupled peptide, EDC, and sulfo-NHS. The scheme of the conjugation reaction of KLVFF peptide with carboxylate Pluronic F127 is shown in Figure 1B. 
command

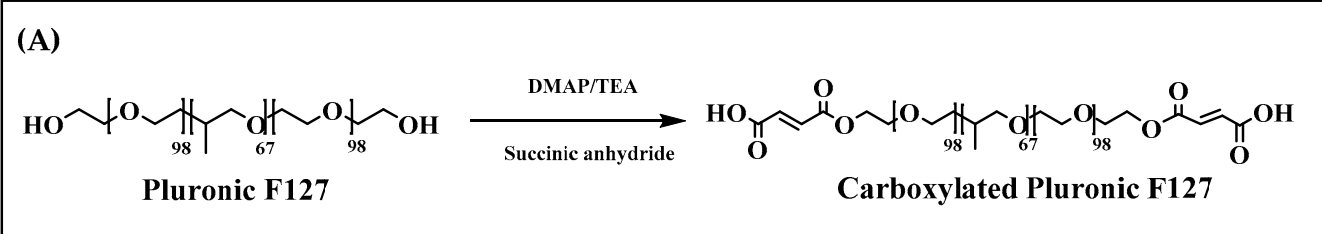

(B)<smiles>CC(C)(CCOCCOC(=O)/C=C/C(=O)O)COCCOCCOC(=O)/C=C/C(=O)O</smiles>

Carboxylated Pluronic F127

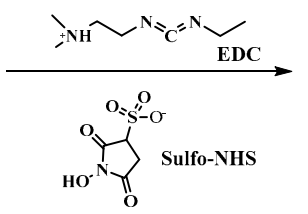

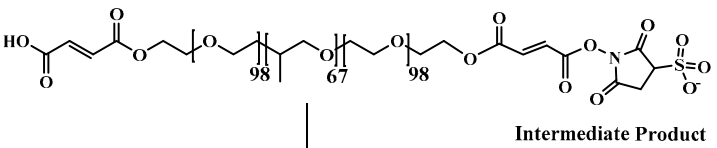

Microemulsions Formulation Curcumin (CUR)

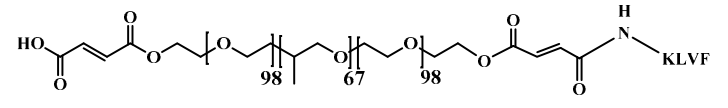

KLVFF-Pluronic F127

Figure 1. The illustration of synthetic route of carboxylated Pluronic F127 (A) Schematic representations of the conjugation reaction of KLVFF peptide with carboxylate Pluronic F127, and formulation of KLVFF-Cur-ME (B).

\subsection{Fourier Transform Infrared Spectroscopy (FTIR)}

The FTIR spectra were obtained by using a Nicolet iS5 FTIR spectrometer (Thermo Scientific, Waltham, MA, USA), which was operated in the range of $4000-400 \mathrm{~cm}^{-1}$. Pluronic and carboxylated Pluronic were physically mixed with potassium bromide and compressed into a disk using a Specac (Kent, UK) hydraulic press before scanning.

\subsection{Differential Scanning Calorimetry (DSC)}

The DSC curves of Pluronic F127, COOH-Pluronic F127, and KLVFF-Pluronic F127 were obtained using a differential scanning calorimeter (DSC8000, PerkinElmer, Waltham, MA, USA) equipped with a heat flow sensor, and joined via the TA Controller TC 15 interface to a computer. Measurements were driven by Pyris $^{\mathrm{TM}}$ software version 13.2.1.0007 (PerkinElmer, Waltham, MA, USA). Samples for DSC measurements were weighed using a Mettler Toledo AT 261 (Columbus, OH, USA) microbalance $( \pm 0.01 \mathrm{mg})$ and sealed in $40 \mu \mathrm{L}$ standard aluminum crucibles with a single hole punched in the lid. The total mass of a sample was between 3 and $5 \mathrm{mg}$. An empty pan of the same type was employed as a reference. DSC scans of each mixture were performed at a heating rate of $5^{\circ} \mathrm{C} / \mathrm{min}$ in the temperature range of $25-200{ }^{\circ} \mathrm{C}$. The DSC cell was purged with a stream of nitrogen at a rate of $50 \mathrm{~mL} / \mathrm{min}$.

\subsection{Solubility of Curcumin}

To find out the appropriate ratios of oils, surfactants, and co-surfactants as excipients for microemulsions (ME) formulation, the solubility of curcumin in various oils, surfactants, and co-surfactants was investigated by adding excess curcumin into $2 \mathrm{~mL}$ of each vehicle. The mixtures were mixed under stirring for $24 \mathrm{~h}$. After equilibrium for $24 \mathrm{~h}$ at room temperature, samples were centrifuged at $5000 \times \mathrm{g}$ rpm for $30 \mathrm{~min}$. The supernatant was diluted with ethanol. The concentration of solubilized curcumin was determined spectrophotometrically at the maximum wavelength of $465 \mathrm{~nm}$. Solubility was carried out in triplicate. 


\subsection{Pseudo-Ternary Phase Diagram Construction}

Pseudo-ternary phase diagrams were constructed to determine the region into which the maximum amount of ME formation occurred. The appropriate components from the result of the solubility study were selected to prepare ME by the spontaneous emulsification technique [42]. Surfactants (mixture of TWEEN 80 and KLVFF-Pluronic F127 in the ratio 1:1) and co-surfactants (ethanol, PEG 400, and PG), namely, Smix, were mixed in different ratios to prepare $\mathrm{ME}$ according to the area existing in the phase diagram. For the construction of the phase diagram, the mixtures of oil, Smix, and water at different ratios were formulated using a titration method under continuous stirring until a transparent ME was formed. The determination of the ME region was performed by visual observation for the turbidity. The samples were classified as ME when they appeared visually as clear liquids. Pseudo-ternary phase diagrams were drawn using SigmaPlot software version 11.0 (Systat Software, Inc., Chicago, IL USA), the areas of the ME regions were measured by ImageJ $1.47 \mathrm{v}$ software (National Institutes of Health, Bethesda, MD, USA).

\subsection{Curcumin-Loaded KLVFF-Pluronic F127 Microemulsions (KLVFF-Cur-ME)}

From pseudo-ternary phase diagrams, the one showing the maximum region for $\mathrm{ME}$ was selected to be considered as an optimized ratio for drug-loaded ME formulation. Various formulations were investigated in terms of droplet size, zeta potential, polydispersity index (PDI), transparency, $\mathrm{pH}$, and conductivity to obtain an optimized formulation. The formulation that showed satisfactory results was selected for fabricating curcumin-loaded KLVFF-Pluronic F127 microemulsions (KLVFF-Cur-ME).

KLVFF-Cur-ME was prepared by dissolving curcumin into the oil phase by adding the required quantity of Smix and water and stirring to form a clear and transparent dispersion. The characterizations of KLVFF-Cur-ME were investigated for the percentage of transmittance, globule size, zeta potential, conductivity, and $\mathrm{pH}$.

\subsection{Physicochemical Characterization of Microemulsions}

\subsubsection{Conductivity Measurement}

The electrical conductivity of ME was measured with a conductivity meter (Metrohm, Switzerland) equipped with a magnetic stirrer. The conductivity measurement was performed using a conductivity cell (with a cell constant of 1.0) consisting of two platinum plates separated by desired distance and liquid between the platinum plates acting as a conductor.

\subsubsection{Particle Size and Zeta Potential Measurements}

The average droplet size and polydispersity index (PDI) of ME were measured by dynamic light scattering (SZ-100, HORIBA, Kyoto, Japan). All determinations were conducted in triplicate.

\subsubsection{Percent Transmittance Measurement}

The percent transmittance of the system was checked by measuring transmittance at $650 \mathrm{~nm}$ with distilled water as a reference [17,43] by a UV spectrophotometer (UV2600i, Shimadzu, Kyoto, Japan).

\subsection{4. $\mathrm{pH}$ Measurement}

The $\mathrm{pH}$ values of $\mathrm{ME}$ and $\mathrm{COOH}-\mathrm{ME}$ were determined using a digital $\mathrm{pH}$ meter ( $\mathrm{pH}$ meter, Metrohm, Herisau, Switzerland), standardized using $\mathrm{pH} 4$ and 7 buffers before use.

\subsection{Morphology Characterization of KLVFF-Cur-ME}

The TEM micrograph of KLVFF-Cur-ME was obtained to characterize morphology (JEM 2010, JEOL, Tokyo, Japan) at an acceleration voltage of $100 \mathrm{kV}$ and $8000 \times$ magnifica- 
tion. KLVFF-Cur-ME was stained with a 1\% aqueous phosphotungstic acid solution and deposited on the carbon-coated copper grid.

\subsection{Determination of Curcumin Content in KLVFF-Cur-ME}

The curcumin content in KLVFF-Cur-ME was determined using a spectrophotometer at the maximum wavelength of $465 \mathrm{~nm}$. A certain amount of KLVFF-Cur-ME was diluted with ethanol, followed by centrifugation at $5000 \times g$ rpm for $30 \mathrm{~min}$. The supernatant was taken, and the amount of curcumin was analyzed by a UV-visible spectrophotometer [44].

\subsection{Ex Vivo Permeation Study}

Curcumin permeation study was conducted using Franz diffusion cells (V9-CA, PermeGear, Hellertown, PA, USA) through the porcine nasal mucosa. Freshly excised porcine nasal mucosa, obtained from the slaughterhouse, was immediately soaked in phosphate buffer ( $\mathrm{pH}$ 6.4) The protocol for the use of cadavers was approved by the Animal Care and Use Committee, Faculty of Veterinary Medicine, Chiang Mai University, Thailand (FVM-CMU-ICUC Ref. No. R5/2563). Fresh porcine nasal mucosa with a thickness of $0.2 \mathrm{~mm}$ was mounted between donor and receptor compartments with a volume capacity of $12.5 \mathrm{~mL}$. KLVFF-Cur-ME equivalent to a similar amount of curcumin in the solution was placed into the donor compartment. At the same time, the receptor was filled with phosphate-buffered saline (PBS, $\mathrm{pH}$ 6.4), which was maintained at $37^{\circ} \mathrm{C}$ under continuous stirring. A one milliliter aliquot was taken at different time intervals and replaced with an equal volume of PBS. After suitable dilution, the sample was analyzed for curcumin content by HPLC.

\subsection{HPLC Analysis of Permeated Curcumin}

The samples obtained from the receptor compartment of Franz diffusion cell were analyzed by HPLC. The separation was performed on a reverse-phase C18 column $(250 \mathrm{~mm} \times 4.6 \mathrm{~mm}$, i. d. $5 \mu \mathrm{m}$ particle size). The elution was carried out with isocratic solvent systems with a flow rate of $1.2 \mathrm{~mL} / \mathrm{min}$ at ambient temperature. The mobile phase consisted of a 50:50 (v:v) mixture of acetonitrile and 2\% acetic acid in water. The UV detector was set at a wavelength of $424 \mathrm{~nm}$.

\subsection{Nasal Ciliotoxicity Study}

Freshly excised porcine nasal mucosa was obtained from the slaughterhouse and immediately soaked in phosphate buffer ( $\mathrm{pH}$ 6.4). The cartilage was gently removed to isolate nasal mucosa. Each piece of the porcine nasal mucosa with even thickness $(0.2 \mathrm{~mm})$ was mounted on Franz diffusion cell with the positive control (isopropyl alcohol) negative control (PBS pH 6.4) and KLVFF-Cur-ME for $2 \mathrm{~h}$. After that, all pieces of mucosa were rinsed with PBS ( $\mathrm{pH}$ 6.4) and soaked in a 10\% v/v formalin solution overnight. Each mucosa was $7 \mathrm{~mm}$ thick and fixed in paraffin blocks. Fine pieces were stained by eosin and hematoxylin. The prepared slides were observed under an inverted microscope (Motic, AE2000, Richmond, BC, Canada) with a magnification of 10×, captured to evaluate any damage to the nasal mucosa. The protocol for the use of cadavers was approved by the Animal Care and Use Committee, Faculty of Veterinary Medicine, Chiang Mai University, Thailand (FVM-CMU-ICUC Ref. No. R5/2563).

\subsection{Statistical Analysis}

All data were presented as mean \pm SEM, $n=3$ experiments. $t$-test was used to determine a significant difference between the means of the two groups. Statistical analysis of data was completed using an analysis of variance (one-way ANOVA), followed by Newman-Keuls method as a post hoc test to evaluate the significance of differences. In all cases, a value of $p<0.05$ was considered statistically significant. 


\section{Results and Discussion}

\subsection{Synthesis and Characterization of COOH-Pluronic F127 and KLVFF-Pluronic F127}

Carboxylated Pluronic F127 (COOH-Pluronic F127) was derivatized through the reaction of Pluronic-OH with succinic anhydride described in Section 2.2. The percentage yield of COOH-Pluronic F127 was $85.47 \pm 0.17 \%$. From the FTIR spectrum (Figure 2), the carbonyl stretch $\mathrm{C}=\mathrm{O}$ of a carboxylic acid in $\mathrm{COOH}-$ Pluronic F127 (blue line) appeared at about $1734 \mathrm{~cm}^{-1}$ [45]. In contrast, the carbonyl stretch $\mathrm{C}=\mathrm{O}$ of a carboxylic acid did not occur on the FTIR spectrum of Pluronic F-127 (red line), indicating the successful transformation of the hydroxyl group of Pluronic F127 to the carboxyl group [46]. Moreover, a strong wideband for the $\mathrm{O}-\mathrm{H}$ stretch appeared as a broadband in the region $3300-2500 \mathrm{~cm}^{-1}$, centered at around $2882 \mathrm{~cm}^{-1}$ [47], and the C-O stretch appears at about $1101 \mathrm{~cm}^{-1}$ [48] for $\mathrm{COOH}-$ Pluronic F127 (blue line) revealed the conversion of OH to COOH. After the KLVFF conjugation (pink line), the typical bands of the amide carbonyl group $(\mathrm{O}=\mathrm{C}-\mathrm{Nh})$ and imino groups of KLVFF units were observed at $1618 \mathrm{~cm}^{-1}$ and $1556 \mathrm{~cm}^{-1}$, respectively [49]. The stretching variation absorbance of N-Hat 3200-3479 $\mathrm{cm}^{-1}$ [50] and an obvious peak at $1647 \mathrm{~cm}^{-1}$ arising from the $\mathrm{C}=\mathrm{O}$ stretching vibration [50] were observed from the FTIR spectroscopy, supporting the existence of KLVFF.

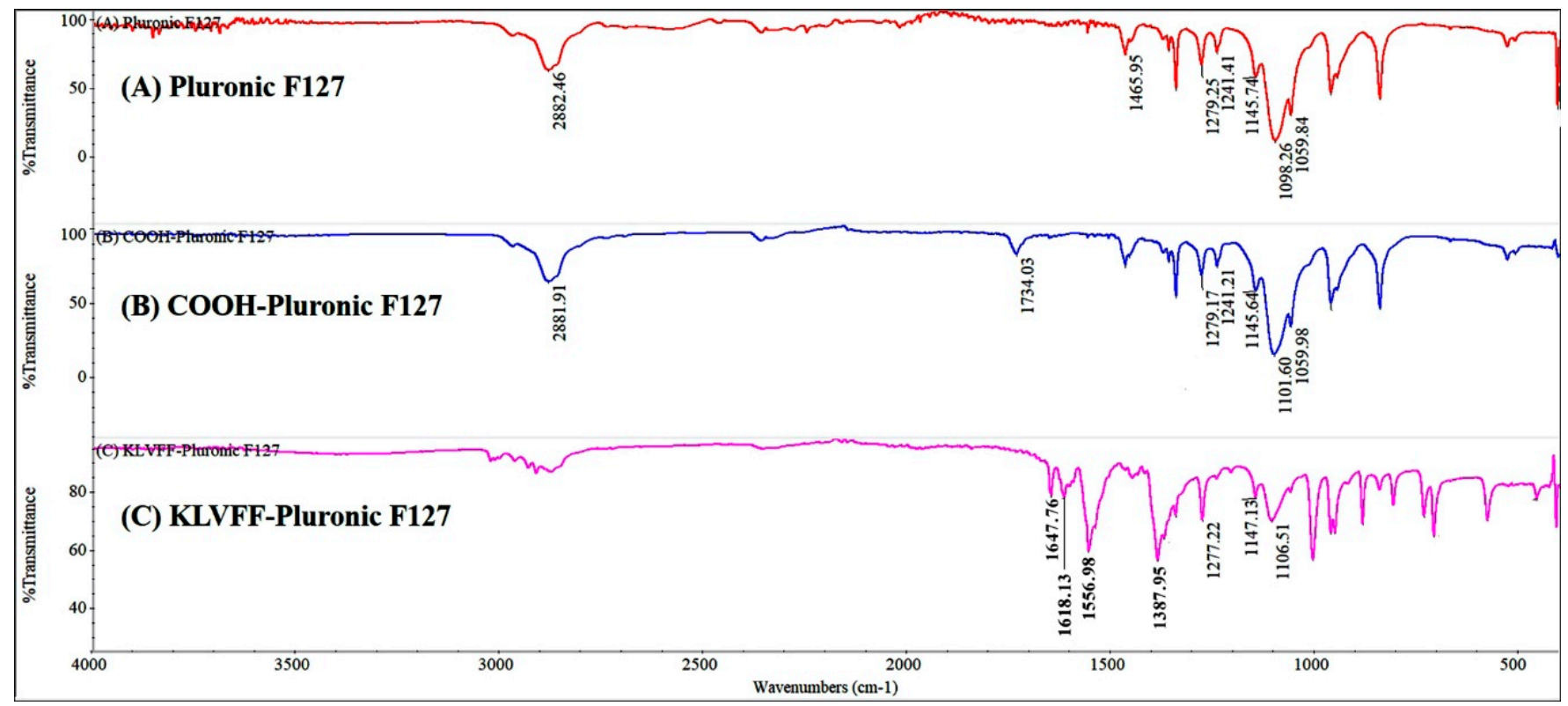

Figure 2. Fourier transform infrared spectra of (A) Pluronic F127, (B) COOH-Pluronic F127, and (C) KLVFF-Pluronic F127.

Differential scanning calorimetry could be used to determine the phase state of a compound. It can also be used to observe the fusion and crystallization characteristics of polymers [51]. After increasing the temperature, the sample was melted at the melting temperature (Tm) which resulted in an endothermic peak in the DSC curve [51]. The melting endothermic peak that was the temperature at which the solid material melted $(\mathrm{Tm})$ is a very important result for the characterization of any material and especially for the energetic materials [51]. The DSC diagrams are shown in Figure 3; the Tm of Pluronic F127 compared with that of COOH-Pluronic F127 declined from 55.40 to $48.45^{\circ} \mathrm{C}$. The FTIR spectra and DSC thermograms indicated the conversion of OH groups of Pluronic F127 to $\mathrm{COOH}$ groups, while the Tm of COOH-Pluronic F127 compared with KLVFF-Pluronic F127 declined from 48.45 to $46.69^{\circ} \mathrm{C}$. The decrease in the Tm of KLVFF.Pluronic F127 might have resulted from the connection of KLVFF to COOH-Pluronic F127. 


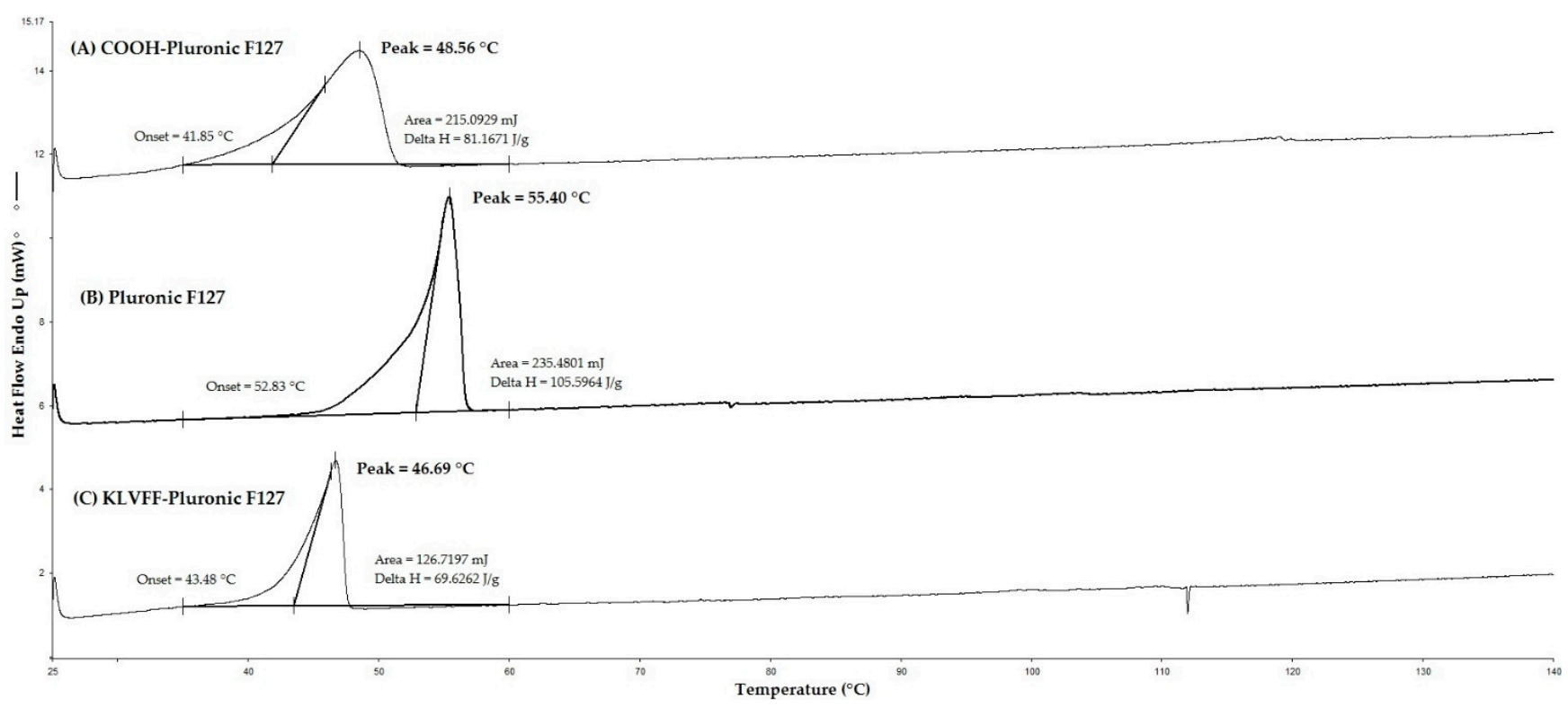

Figure 3. DSC thermogram of (A) Pluronic F127, (B) COOH-Pluronic F127, and (C) KLVFF-Pluronic F127.

\subsection{Solubility of Curcumin}

The solubility of curcumin in various oils and co-surfactants was analyzed to screen the components for microemulsions. Selecting the best oil phase was required for the maximum solubility potential for the drug to cover a larger ME region in the ternary plots and obtain a stable ME [17,52]. Solubility data for the curcumin in oil, surfactant, and co-surfactant are shown in Figure 4. Curcumin showed the highest solubility in oleic acid $(1.68 \pm 0.21 \mathrm{mg} / \mathrm{mL})$. compared to other oils. Therefore, oleic acid was fixed as the oil phase for further studies. On the other hand, the co-surfactant selected for this study was ethanol, showing the highest solubility $(3.50 \pm 0.33 \mathrm{mg} / \mathrm{mL})$ for curcumin. TWEEN 80 has been reported to significantly enhance drug concentration in the brain via the intranasal route [53]. Although TWEEN 80 performed the highest solubility $(25.20 \mathrm{mg} / \mathrm{mL})$ this study aimed to develop KLVFF-conjugated microemulsions via coupling the amino group of the KLVFF peptide with the carboxylic group on modified Pluronic (Pluronic-COOH). Therefore, the mixture of TWEEN 80 and KLVFF-Pluronic F127 (Tween 80-KLVFF-COOH$\mathrm{Plu}$ ) was used as a surfactant in this study, which presented the solubility of curcumin at $6.35 \pm 0.94 \mathrm{mg} / \mathrm{mL}$.

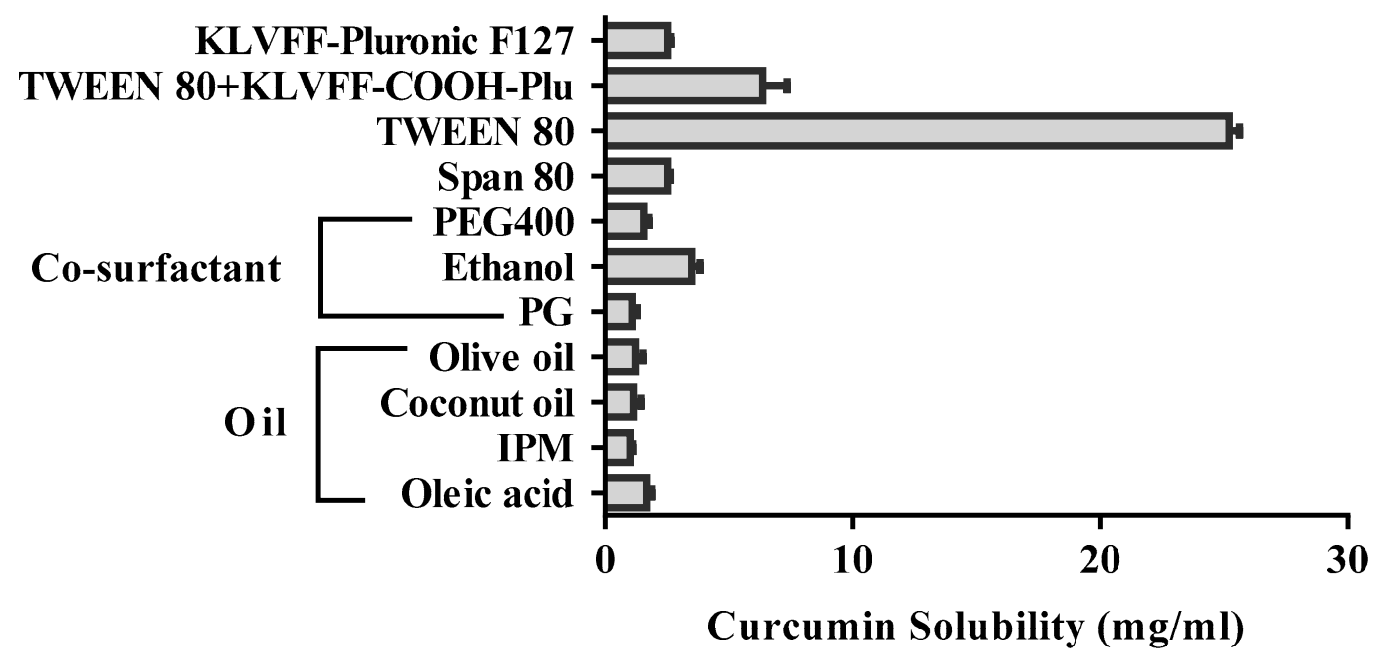

Figure 4. Solubility data for curcumin in oil, surfactant, and co-surfactant. 


\subsection{Pseudo-Ternary Phase Diagram Construction}

The pseudo-ternary phase was constructed from the components that showed the maximum solubility, as shown in Figure 5. The microemulsions system consisted of oleic acid as the oil phase, a mixture of TWEEN 80 and COOH-Pluronic F127 as a surfactant, and ethanol as the co-surfactant. The gray region in the diagram exhibits the microemulsions region. The weight ratios of the surfactant/co-surfactant (Smix) were 1:1, 2:1, 3:1, and $4: 1$. The largest region $(25.7 \%)$ was observed in the $1: 1$ weight ratio of the surfactant/cosurfactant, while the smallest region $(1.1 \%)$ was presented in the $4: 1$ weight ratio. The result demonstrated that an increase in the surfactant/co-surfactant mixture ratio resulted in a decrease in the microemulsions region. Our results conformed to the observations reported by other works [54]. Increasing TWEEN 80 promoted the increasing incorporation of water, leading to the turbidity of the system [15]. As described above, the largest microemulsions region was for 1:1 Smix. Therefore, it was selected as the optimal system for incorporating curcumin, revealing formulations F1, F2, F3, F4, and F5, as shown in Table 1.
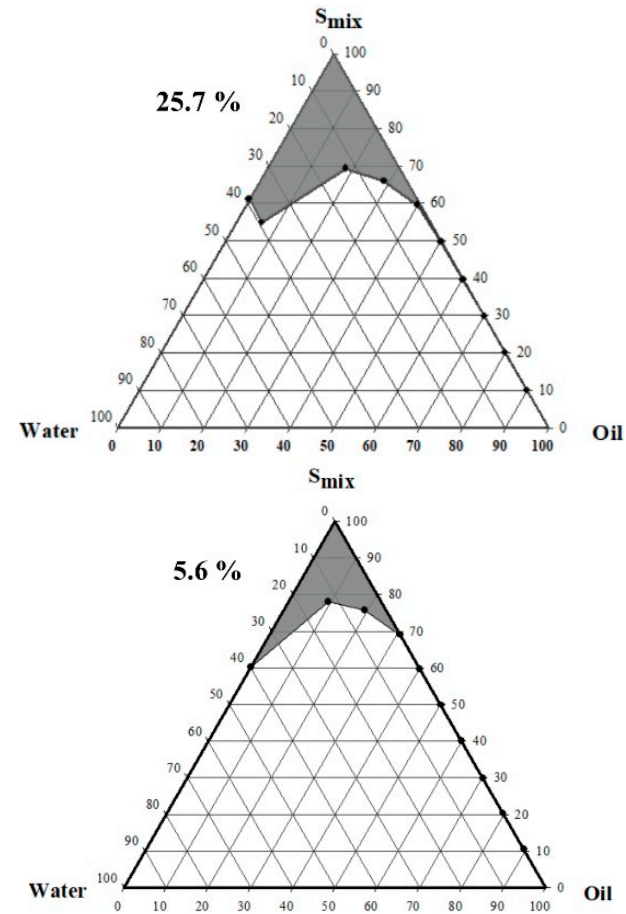
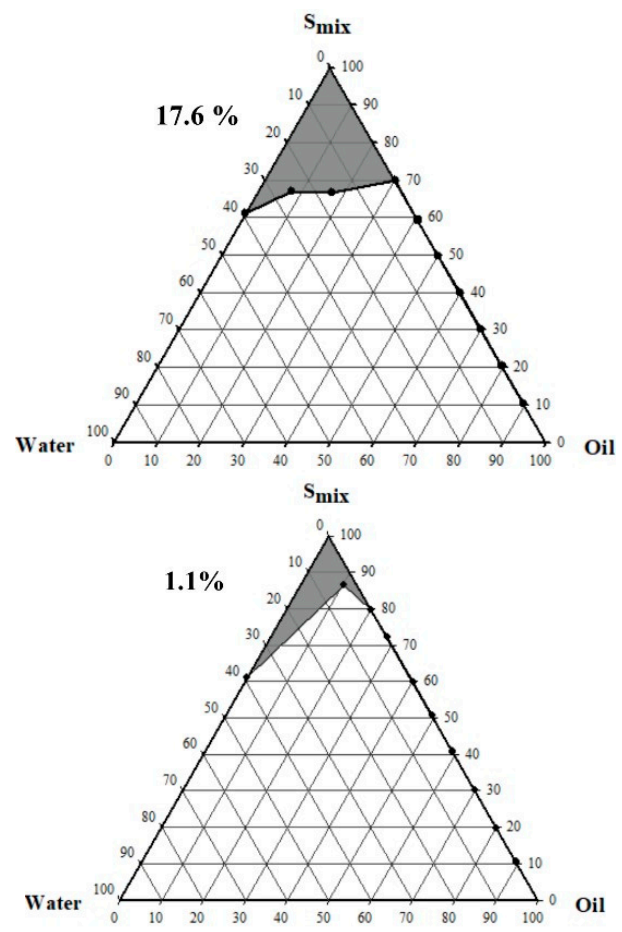

Figure 5. Pseudo-ternary phase diagrams at different ratios of surfactant and co-surfactant (1:1, 2:1, $3: 1,4: 1$ ).

\subsection{Physicochemical Characterization of Microemulsions}

Physicochemical and formulation factors are necessary for the rational design of a dosage form [55]. The expected properties of the system for a transnasal administration should have revealed non-irritation, a high permeation, and low clearance from the nasal mucosa. Hence, the physicochemical properties of microemulsions were investigated as tabulated in Table 1 to predict the usability of ME for the transnasal route. The $\mathrm{pH}$ value of formulation should have been close to the nasal secretion, reported around 4.5-6.5 [15], suggesting that the formulations would avoid nasal irritation [56]. The viscosity was one of the parameters that should have been considered for a transnasal application, in which low viscosity displays a facile packing, handling, and hassle-free administration of formulations [57]. Although a higher viscosity facilitates the prolonged retention time of formulation at the nasal cavity, the permeation rate decreased with an increased viscosity [15]. Thus, the formulation should have an optimal viscosity. The viscosity of all formulated MEs in this study was around 40-110 cP. Previous reports indicated that a viscosity between 100 and $200 \mathrm{cP}$ is suitable for nasal administration [58]. The percentage 
transmittance was greater than $95 \%$ for all formulated MEs, indicating a clear dispersion and confirmed transparency properties [59]. Moreover, the appearance of all MEs presented a clear and transparent dispersion as shown in Figure 6A, B. These two findings confirmed that all formulated MEs met the criteria of transparency, which was one of the desired properties of microemulsions [13]. Permeation was affected by the globule size, and a faster permeation was expected when the globule size was small [15]. The globule sizes for all formulated MEs were in the range of 55.4-103.0 nm, which is generally considered to be the globule size of a microemulsions $(\approx 10-150 \mathrm{~nm})$ [60]. Nanocarriers with the size range of 10-200 $\mathrm{nm}$ were reported to easily transport across the BBB by efficiently encapsulating drug molecules and increasing their diffusion through biological membranes compared to the oral route [14]. MEs have small a droplet size and have a higher surface area compared to other formulations; therefore, they are expected to effectively transport the drug through intranasal delivery [16].

Table 1. Physicochemical properties of ME.

\begin{tabular}{|c|c|c|c|c|c|c|c|c|}
\hline Formulation & $\begin{array}{l}\text { Oil: } \\
\text { Smix: } \\
\text { Water }\end{array}$ & $\begin{array}{c}\text { Globule Size } \\
(\mathrm{nm})\end{array}$ & PDI & $\begin{array}{c}\text { Zeta } \\
\text { Potential } \\
(\mathrm{mV})\end{array}$ & $\begin{array}{l}\text { Viscosity } \\
\text { (cP) }\end{array}$ & $\% \mathrm{~T}$ & $\mathrm{pH}$ & $\begin{array}{c}\text { Conductivity } \\
(\mathrm{ms} / \mathrm{cm})\end{array}$ \\
\hline F1 & $10: 60: 30$ & $70.8 \pm 0.9$ & $0.333 \pm 0.037$ & $-0.02 \pm 0.01$ & $72.89 \pm 2.04$ & $95.64 \pm 0.55$ & $4.85 \pm 0.03$ & $0.02 \pm 0.00$ \\
\hline $\mathrm{F} 2$ & $10: 70: 20$ & $80.7 \pm 3.8$ & $0.494 \pm 0.017$ & $-0.1 \pm 0.1$ & $53.44 \pm 0.69$ & $95.81 \pm 0.12$ & $4.96 \pm 0.01$ & $0.02 \pm 0.06$ \\
\hline F3 & $10: 80: 10$ & $55.4 \pm 3.3$ & $0.504 \pm 0.017$ & $-0.1 \pm 0.1$ & $49.78 \pm 3.34$ & $96.06 \pm 0.43$ & $4.88 \pm 0.05$ & $0.02 \pm 0.00$ \\
\hline $\mathrm{F} 4$ & $15: 75: 10$ & $103.0 \pm 2.9$ & $0.316 \pm 0.003$ & $-0.3 \pm 0.3$ & $50.44 \pm 2.04$ & $95.43 \pm 0.43$ & $5.16 \pm 0.04$ & $0.02 \pm 0.01$ \\
\hline F5 & $15: 80: 5$ & $64.6 \pm 2.7$ & $0.471 \pm 0.014$ & $-0.1 \pm 0.2$ & $78.46 \pm 5.58$ & $95.39 \pm 1.63$ & $4.90 \pm 0.03$ & $0.02 \pm 0.00$ \\
\hline KLVFF-Cur-ME & $15: 80: 5$ & $76.1 \pm 2.5$ & $0.405 \pm 0.015$ & $-0.1 \pm 0.7$ & $70.98 \pm 3.02$ & $97.03 \pm 0.01$ & $5.33 \pm 0.02$ & $0.02 \pm 0.01$ \\
\hline
\end{tabular}

(A)
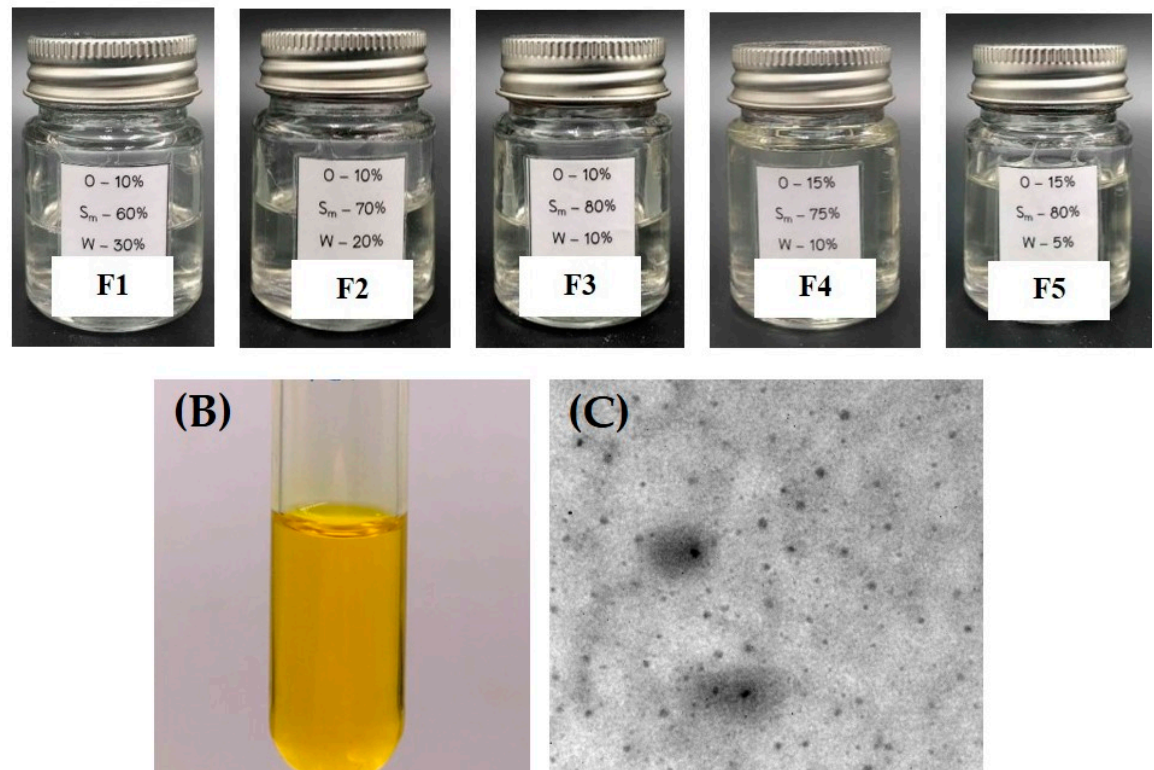

KLVFF-Cur-ME

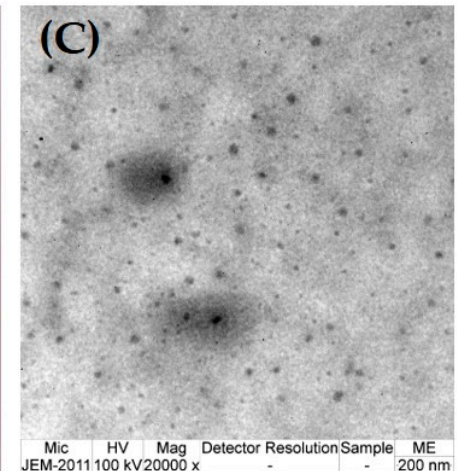

Figure 6. The appearance of blank microemulsions F1-F5 (A), KLVFF-Cur-ME (B), and a transmission electron microscopy image of KLVFF-Cur-ME (C).

Normally, a PDI of close to zero indicates the uniformity of a globule size, while one indicates a polydisperse sample with multiple size populations [61]. Values of 0.2 and below are most commonly deemed acceptable for polymeric nanoparticles, while 0.3 is considered to be acceptable and indicates a homogenous population of phospholipid vesicles [61]. The results exhibited that PDI values were greater than 0.3 , in which the dispersity was likely to be polydisperse. However, the instrument still reported the monodispersity of the samples. The zeta potential values of all MEs were slightly negative (from -0.1 to $-0.3 \mathrm{mV}$ ). It is generally known that the system is stable when the absolute value of zeta 
potential is greater than $30 \mathrm{mV}$, but zeta potential does not fully reflect the stability of the microemulsions [62]. For microemulsions systems containing nonionic surfactants, steric hindrance plays an important role in stability. The stability of microemulsions with a low absolute value of the zeta potential were reported stable [62]. The colloidal stability of MEs with a slightly negative charge was previously discussed [15]. Several reports have shown that MEs containing slightly negative values of the zeta potential have shown a good colloidal stability [17,62-65]. However, only obtaining the zeta potential value is not enough to predict the stability of formulations, and a stability study should be performed to confirm the stability of the formulation in our future study. Based on the above rationale critical quality attributes, F5 was selected for a further study to formulate KLVFF-Cur-ME. From Table 1, KLVFF-Cur-ME showed a slightly increased internal droplet globule size compared to plain ME (F5). This result indicated that curcumin would immerse in the surfactant film around an oily droplet of o/w microemulsions [60]. This may be attributed to the fact that KLVFF-Cur-ME presented a good quality of microemulsions in terms of the globule size, PDI, pH, viscosity, and \% transmittance as described abovw. Moreover, the drug loading content was found to be $80.25 \pm 5.47 \%$ for KLVFF-Cur-ME, indicating the high encapsulation efficiency of the ME.

\subsection{Morphology Characterization of KLVFF-Cur-ME}

The morphology of KLVFF-Cur-ME using TEM revealed a spherical shape with size in the nanoscale $(20-65 \mathrm{~nm})$, as shown in Figure 6C. This result conformed to the globule size distribution measured using photon correlation spectroscopy in Table 1.

\subsection{Ex Vivo Permeation Study}

An ex vivo diffusion study was performed to assess the drug diffusion through a biological membrane simulating the actual in vivo barrier to drug diffusion [66]. The ex vivo drug diffusion study of KLVFF-Cur-ME was studied to acquire a more precise diffusion profile. The ex vivo diffusion profile of free curcumin and KLVFF-Cur-ME is shown in Figure 7, whereby the regression coefficients $\left(r^{2}\right)$ for the zero-order, first-order, and Higuchi models are shown in Table 2. The Higuchi model was better suited to the KLVFF-Cur-ME release rate $\left(r^{2}=0.9222\right)$, indicating a curcumin partitioning through diffusion, since the porcine mucosa acted as a barrier or controlling membrane [67]. The result indicated that the diffusion process of KLVFF-Cur-ME was closer to the reservoir system than the zeroorder (concentration-independent) or first-order (concentration gradient) diffusions [67]. Moreover, the result was also evidenced by the successful diffusion of KLVFF-Cur-ME through the porcine nasal mucosa.

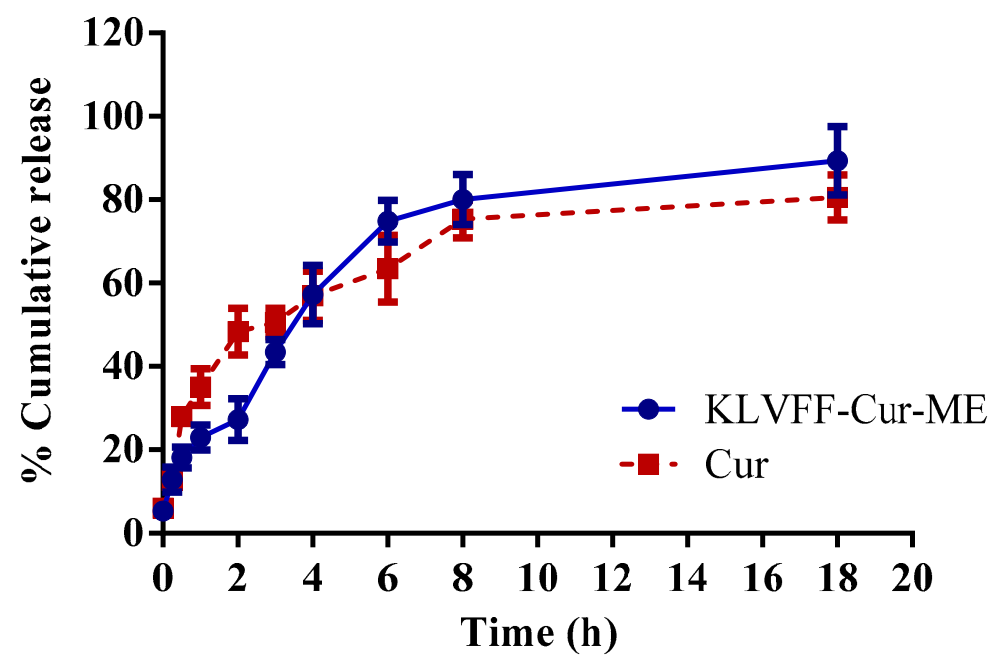

Figure 7. Ex vivo curcumin release profile of curcumin solution and KLVFF-Cur-ME through porcine nasal mucosa membrane. 
Table 2. Release kinetics of curcumin and KLVFF-Cur-ME.

\begin{tabular}{cccc}
\hline & & $r^{2}$ & \\
\hline Formulation & Zero-Order & First-Order & Higuchi \\
\hline Curcumin & 0.6621 & 0.4100 & 0.9044 \\
KLVFF-Cur-ME & 0.7494 & 0.5434 & 0.9222 \\
\hline
\end{tabular}

\subsection{Nasal Ciliotoxicity}

The nasal ciliotoxicity was studied to evaluate the toxic effect of the excipients used for the nasal mucosa formulations. Figure $8 \mathrm{~A}$, the porcine nasal mucosa treated with a mucociliary toxic agent (isopropyl alcohol) showed the destruction of the epithelium layer with damage to internal nasal tissues (arrows). Nasal mucosa treated with the negative control (PBS pH 6.4) showed an intact epithelium layer without tissue damage (Figure 8C). KLVFF-Cur-ME did not exhibit toxicity on tissue damage with an intact epithelium layer, indicating the safety of excipients used in the formulation of KLVFF-Cur-ME in this study (Figure 8B). Our results agreed with other reports, demonstrating the intoxicity of oleic acid and TWEEN 80 [15].

(A) IPA

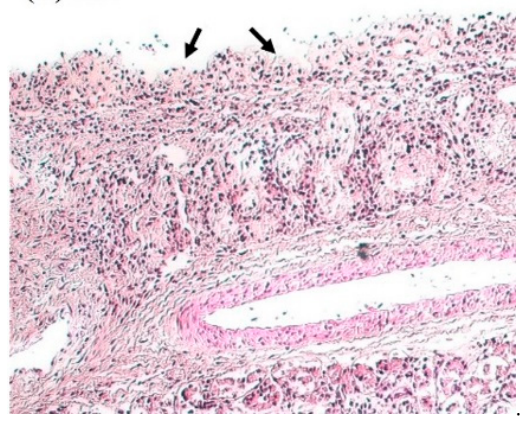

(B) KLVFF-Cur-ME

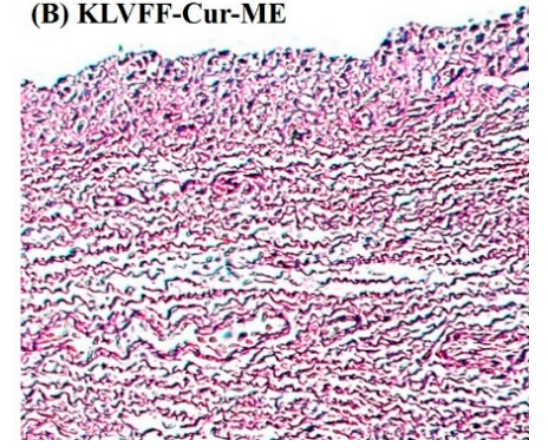

(C).PBS pH 6.4

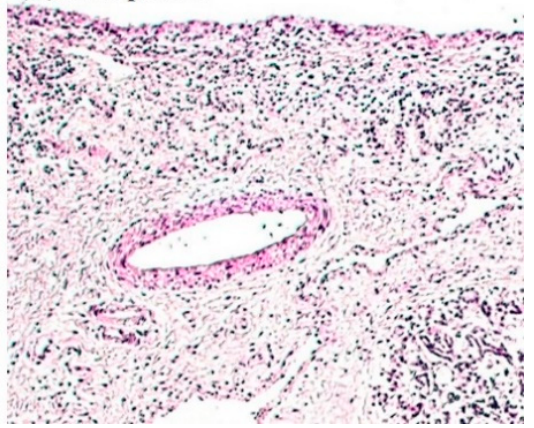

Figure 8. Optical microscopic images $(10 \times)$ of nasal mucosa treated with: $(\mathbf{A})$ positive control—isopropyl alcohol; (B) KLVFF-Cur-ME; (C) negative control-PBS pH 6.4.

\section{Conclusions}

In this study, Cur-ME was prepared using the titration method. A carbodiimide reaction was performed for the KLVFF conjugation. KLVFF-Cur-ME was successfully synthesized with acceptable physicochemical characteristics and was suitable for intranasal administration. The encapsulation of curcumin into the microemulsions improved the solubility and released the profile of curcumin. KLVFF-Cur-ME did not show nasal ciliotoxicity. The kinetic release profile of KLVFF-Cur-ME followed the Higuchi model. The result from the ex vivo permeation study suggested the successful diffusion of KLVFF-Cur-ME through the porcine nasal mucosa. Therefore, KLVFF-Cur-ME may provide a new approach for inhibiting $\mathrm{A} \beta$ aggregation via intranasal administration. However, the potential of the developed KLVFF-Cur-ME for nose-to-brain delivery of curcumin can only be established after in vivo toxicity and biodistribution studies.

Author Contributions: Conceptualization, R.P. and C.C.; Data curation, R.P.; Formal analysis, R.P. and S.L.; Investigation, R.P., W.T. and K.T.; Methodology, R.P., W.T. and K.T.; Supervision, C.C.; Validation, R.P.; Visualization, S.L.; Writing—original draft, R.P.; Writing—review \& editing, C.C. All authors have read and agreed to the published version of the manuscript.

Funding: This research was funded by the Thailand research fund (TRF) grant number MRG6280112 for young researchers and was partially funded by Chiang Mai University.

Institutional Review Board Statement: Not applicable.

Informed Consent Statement: Not applicable. 


\section{Data Availability Statement: Not applicable.}

Acknowledgments: We appreciate the financial support by the Thailand research fund (TRF: research fund code MRG6280112 for young researchers. Part of this research was supported by Center of Excellence for Innovation in Analytical Science and Technology for Biodiversity-based Economic and Society (I-ANALY-S-T_B.BES-CMU), Chiang Mai University, Chiang Mai, Thailand. We are thankful to the Faculty of Pharmacy, Chiang Mai University, for providing the facility and equipment.

Conflicts of Interest: The authors declare no conflict of interest.

\section{References}

1. Uddin, M.S.; Mamun, A.A.; Takeda, S.; Sarwar, M.S.; Begum, M.M. Analyzing the chance of developing dementia among geriatric people: A cross-sectional pilot study in Bangladesh. Psychogeriatrics 2019, 19, 87-94. [CrossRef]

2. Salomone, S.; Caraci, F.; Leggio, G.M.; Fedotova, J.; Drago, F. New pharmacological strategies for treatment of Alzheimer's disease: Focus on disease modifying drugs. Br. J. Clin. Pharmacol. 2012, 73, 504-517. [CrossRef]

3. Han, X.; Yan, J.; Ren, L.; Xue, M.; Yuan, Z.; Wang, T.; Yan, Z.; Yin, L.; Yang, L.; Qin, C. Preparation and evaluation of orally disintegrating film containing donepezil for Alzheimer disease. J. Drug Deliv. Sci. Technol. 2019, 54, 101321. [CrossRef]

4. Lu, C.-T.; Zhao, Y.-Z.; Wong, H.L.; Cai, J.; Peng, L.; Tian, X.-Q. Current approaches to enhance CNS delivery of drugs across the brain barriers. Int. J. Nanomed. 2014, 9, 2241. [CrossRef] [PubMed]

5. $\quad$ Patel, R.B.; Patel, M.R.; Bhatt, K.K.; Patel, B.G.; Gaikwad, R.V. Microemulsion-based drug delivery system for transnasal delivery of Carbamazepine: Preliminary brain-targeting study. Drug Deliv. 2016, 23, 207-213. [CrossRef]

6. Keller, L.-A.; Merkel, O.; Popp, A. Intranasal drug delivery: Opportunities and toxicologic challenges during drug development. Drug Deliv. Transl. Res. 2021, 1-23. [CrossRef] [PubMed]

7. Erdő, F.; Bors, L.A.; Farkas, D.; Bajza, Á.; Gizurarson, S. Evaluation of intranasal delivery route of drug administration for brain targeting. Brain Res. Bull. 2018, 143, 155-170. [CrossRef] [PubMed]

8. Espinoza, L.C.; Silva-Abreu, M.; Clares, B.; Rodríguez-Lagunas, M.J.; Halbaut, L.; Cañas, M.-A.; Calpena, A.C. Formulation strategies to improve nose-to-brain delivery of donepezil. Pharmaceutics 2019, 11, 64. [CrossRef]

9. Sonvico, F.; Clementino, A.; Buttini, F.; Colombo, G.; Pescina, S.; Stanisçuaski Guterres, S.; Raffin Pohlmann, A.; Nicoli, S. Surface-modified nanocarriers for nose-to-brain delivery: From bioadhesion to targeting. Pharmaceutics 2018, 10, 34. [CrossRef]

10. Peltonen, L.; Singhal, M.; Hirvonen, J. 1-Principles of nanosized drug delivery systems. In Nanoengineered Biomaterials for Advanced Drug Delivery; Mozafari, M., Ed.; Elsevier: Amsterdam, The Netherlands, 2020; pp. 3-25. [CrossRef]

11. Hong, Y.; Rao, Y. Current status of nanoscale drug delivery systems for colorectal cancer liver metastasis. Biomed. Pharmacother. 2019, 114, 108764. [CrossRef]

12. Bergonzi, M.; Hamdouch, R.; Mazzacuva, F.; Isacchi, B.; Bilia, A. Optimization, characterization and in vitro evaluation of curcumin microemulsions. LWT-Food Sci. Technol. 2014, 59, 148-155. [CrossRef]

13. Kizilbash, N.; Farooq, S.; Foorginezhad, S.; Ambreen, J.; Zaidi, A.H.; Khachfe, H.M. Microemulsions: Unique Properties, Pharmacological Applications and Targeted Drug Delivery. Front. Nanotechnol. 2021, 69.

14. Shah, B. Microemulsion as a promising carrier for nose to brain delivery: Journey since last decade. J. Pharm. Investig. 2021, 51, 611-634. [CrossRef]

15. Acharya, S.P.; Pundarikakshudu, K.; Panchal, A.; Lalwani, A. Preparation and evaluation of transnasal microemulsion of carbamazepine. Asian J. Pharm. Sci. 2013, 8, 64-70. [CrossRef]

16. Froelich, A.; Osmałek, T.; Jadach, B.; Puri, V.; Michniak-Kohn, B. Microemulsion-Based Media in Nose-to-Brain Drug Delivery. Pharmaceutics 2021, 13, 201. [CrossRef] [PubMed]

17. Shah, B.M.; Misra, M.; Shishoo, C.J.; Padh, H. Nose to brain microemulsion-based drug delivery system of rivastigmine: Formulation and ex-vivo characterization. Drug Deliv. 2015, 22, 918-930. [CrossRef] [PubMed]

18. Shah, B.; Khunt, D.; Misra, M.; Padh, H. Formulation and in-vivo pharmacokinetic consideration of intranasal microemulsion and mucoadhesive microemulsion of rivastigmine for brain targeting. Pharm. Res. 2018, 35, 1-10. [CrossRef] [PubMed]

19. Mehra, N.K.; Mishra, V.; Jain, N.K. Receptor-based targeting of therapeutics. Ther. Deliv. 2013, 4, 369-394. [CrossRef]

20. Gopalan, D.; Pandey, A.; Udupa, N.; Mutalik, S. Receptor specific, stimuli responsive and subcellular targeted approaches for effective therapy of Alzheimer: Role of surface engineered nanocarriers. J. Control. Release 2020, 319, 183-200. [CrossRef]

21. Brenza, T.M.; Ghaisas, S.; Ramirez, J.E.V.; Harischandra, D.; Anantharam, V.; Kalyanaraman, B.; Kanthasamy, A.G.; Narasimhan, B. Neuronal protection against oxidative insult by polyanhydride nanoparticle-based mitochondria-targeted antioxidant therapy. Nanomed. Nanotechnol. Biol. Med. 2017, 13, 809-820. [CrossRef]

22. Song, Q.; Song, H.; Xu, J.; Huang, J.; Hu, M.; Gu, X.; Chen, J.; Zheng, G.; Chen, H.; Gao, X. Biomimetic ApoE-reconstituted high density lipoprotein nanocarrier for blood-brain barrier penetration and amyloid beta-targeting drug delivery. Mol. Pharm. 2016, 13, 3976-3987. [CrossRef]

23. Papadia, K.; Markoutsa, E.; Mourtas, S.; Giannou, A.D.; La Ferla, B.; Nicotra, F.; Salmona, M.; Klepetsanis, P.; Stathopoulos, G.T.; Antimisiaris, S.G. Multifunctional LUV liposomes decorated for BBB and amyloid targeting. A. In vitro proof-of-concept. Eur. J. Pharm. Sci. 2017, 101, 140-148. [CrossRef] 
24. Khallaf, R.A.; Aboud, H.M.; Sayed, O.M. Surface modified niosomes of olanzapine for brain targeting via nasal route; preparation, optimization, and in vivo evaluation. J. Liposome Res. 2020, 30, 163-173. [CrossRef] [PubMed]

25. Michno, W.; Wehrli, P.; Meier, S.R.; Sehlin, D.; Syvänen, S.; Zetterberg, H.; Blennow, K.; Hanrieder, J. Chemical imaging of evolving amyloid plaque pathology and associated $\mathrm{A} \beta$ peptide aggregation in a transgenic mouse model of Alzheimer's disease. J. Neurochem. 2020, 152, 602-616. [CrossRef] [PubMed]

26. Horsley, J.R.; Jovcevski, B.; Wegener, K.L.; Yu, J.; Pukala, T.L.; Abell, A.D. Rationally designed peptide-based inhibitor of A $\beta 42$ fibril formation and toxicity: A potential therapeutic strategy for Alzheimer's disease. Biochem. J. 2020, 477, 2039-2054. [CrossRef] [PubMed]

27. Huang, Q.; Zhao, Q.; Peng, J.; Yu, Y.; Wang, C.; Zou, Y.; Su, Y.; Zhu, L.; Wang, C.; Yang, Y. Peptide-polyphenol (KLVFF/EGCG) binary modulators for inhibiting aggregation and neurotoxicity of amyloid- $\beta$ peptide. ACS Omega 2019, 4, 4233-4242. [CrossRef]

28. Tjernberg, L.O.; Näslund, J.; Lindqvist, F.; Johansson, J.; Karlström, A.R.; Thyberg, J.; Terenius, L.; Nordstedt, C. Arrest of-Amyloid Fibril Formation by a Pentapeptide Ligand (*). J. Biol. Chem. 1996, 271, 8545-8548. [CrossRef] [PubMed]

29. Khalili Samani, E.; Mofid, M.R.; Malakoutikhah, M. The effect of terminal groups and halogenation of KLVFF peptide on its activity as an inhibitor of $\beta$-amyloid aggregation. J. Pept. Sci. 2020, 26, e3227. [CrossRef]

30. Castelletto, V.; Ryumin, P.; Cramer, R.; Hamley, I.; Taylor, M.; Allsop, D.; Reza, M.; Ruokolainen, J.; Arnold, T.; Hermida-Merino, D. Self-assembly and anti-amyloid cytotoxicity activity of amyloid beta peptide derivatives. Sci. Rep. 2017, 7, 43637. [CrossRef]

31. Plissonneau, M.; Pansieri, J.; Heinrich-Balard, L.; Morfin, J.-F.; Stransky-Heilkron, N.; Rivory, P.; Mowat, P.; Dumoulin, M.; Cohen, R.; Allémann, E. Gd-nanoparticles functionalization with specific peptides for ß-amyloid plaques targeting. J. Nanobiotechnol. 2016, 14, 60. [CrossRef]

32. Abadi, A.J.; Mirzaei, S.; Mahabady, M.K.; Hashemi, F.; Zabolian, A.; Hashemi, F.; Raee, P.; Aghamiri, S.; Ashrafizadeh, M.; Aref, A.R. Curcumin and its derivatives in cancer therapy: Potentiating antitumor activity of cisplatin and reducing side effects. Phytother. Res. 2021, 36, 189-213. [CrossRef]

33. Ashrafizadeh, M.; Najafi, M.; Makvandi, P.; Zarrabi, A.; Farkhondeh, T.; Samarghandian, S. Versatile role of curcumin and its derivatives in lung cancer therapy. J. Cell. Physiol. 2020, 235, 9241-9268. [CrossRef]

34. Lee, W.-H.; Loo, C.-Y.; Bebawy, M.; Luk, F.; Mason, R.S.; Rohanizadeh, R. Curcumin and its derivatives: Their application in neuropharmacology and neuroscience in the 21st century. Curr. Neuropharmacol. 2013, 11, 338-378. [CrossRef]

35. Mishra, S.; Palanivelu, K. The effect of curcumin (turmeric) on Alzheimer's disease: An overview. Ann. Indian Acad. Neurol. 2008, 11, 13. [CrossRef]

36. Kim, H.; Park, B.-S.; Lee, K.-G.; Choi, C.Y.; Jang, S.S.; Kim, Y.-H.; Lee, S.-E. Effects of naturally occurring compounds on fibril formation and oxidative stress of $\beta$-amyloid. J. Agric. Food Chem. 2005, 53, 8537-8541. [CrossRef] [PubMed]

37. Ono, K.; Hasegawa, K.; Naiki, H.; Yamada, M. Curcumin has potent anti-amyloidogenic effects for Alzheimer's $\beta$-amyloid fibrils in vitro. J. Neurosci. Res. 2004, 75, 742-750. [CrossRef] [PubMed]

38. Jakubowski, J.M.; Orr, A.A.; Le, D.A.; Tamamis, P. Interactions between curcumin derivatives and amyloid- $\beta$ fibrils: Insights from molecular dynamics simulations. J. Chem. Inf. Modeling 2019, 60, 289-305. [CrossRef] [PubMed]

39. Karthikeyan, A.; Senthil, N.; Min, T. Nanocurcumin: A promising candidate for therapeutic applications. Front. Pharmacol. 2020, 11, 487. [CrossRef]

40. Phongpradist, R.; Chittasupho, C.; Okonogi, S.; Siahaan, T.; Anuchapreeda, S.; Ampasavate, C.; Berkland, C. LFA-1 on leukemic cells as a target for therapy or drug delivery. Curr. Pharm. Des. 2010, 16, 2321-2330. [CrossRef] [PubMed]

41. Gohil, S.; Padmanabhan, A.; Deschamps, J.; Nair, L. Chitosan-based scaffolds for growth factor delivery. In Chitosan Based Biomaterials Volume 2; Elsevier: Amsterdam, The Netherlands, 2017; pp. 175-207.

42. Parveen, R.; Akhtar, N.; Mahmood, T. Topical microemulsion containing Punica granatum extract: Its control over skin erythema and melanin in healthy Asian subjects. Adv. Dermatol. Allergol. Postępy Dermatol. I Alergol. 2014, 31, 351. [CrossRef]

43. Gandhi, J.; Suthar, D.; Patel, H.; Shelat, P.; Parejiya, P. Development and characterization of microemulsion based topical gel of essential oil of clove (Syzygium aromaticum) for superficial fungal infections. Adv. Tradit. Med. 2021, 21, 519-534. [CrossRef]

44. Wang, S.; Chen, P.; Zhang, L.; Yang, C.; Zhai, G. Formulation and evaluation of microemulsion-based in situ ion-sensitive gelling systems for intranasal administration of curcumin. J. Drug Target. 2012, 20, 831-840. [CrossRef]

45. Tan, J.M.; Karthivashan, G.; Arulselvan, P.; Fakurazi, S.; Hussein, M.Z. Characterization and in vitro sustained release of silibinin from $\mathrm{pH}$ responsive carbon nanotube-based drug delivery system. J. Nanomater. 2014, 2014, 1.

46. Li, Y.-Y.; Li, L.; Dong, H.-Q.; Cai, X.-J.; Ren, T.-B. Pluronic F127 nanomicelles engineered with nuclear localized functionality for targeted drug delivery. Mater. Sci. Eng. C 2013, 33, 2698-2707. [CrossRef] [PubMed]

47. Mitchell, C.J.; Yang, G.-R.; Senkevich, J.J. Adhesion aspects of poly (p-xylylene) to $\mathrm{SiO}_{2}$ surfaces using $\gamma$-methacryloxy propyltrimethoxysilane as an adhesion promoter. J. Adhes. Sci. Technol. 2006, 20, 1637-1647. [CrossRef]

48. Yu, S.; Liu, J.; Zhu, W.; Hu, Z.-T.; Lim, T.-T.; Yan, X. Facile room-temperature synthesis of carboxylated graphene oxide-copper sulfide nanocomposite with high photodegradation and disinfection activities under solar light irradiation. Sci. Rep. 2015, 5, 16369. [CrossRef]

49. Wang, Y.-J.; Pan, M.-H.; Cheng, A.-L.; Lin, L.-I.; Ho, Y.-S.; Hsieh, C.-Y.; Lin, J.-K. Stability of curcumin in buffer solutions and characterization of its degradation products. J. Pharm. Biomed. Anal. 1997, 15, 1867-1876. [CrossRef]

50. Borzooeian, Z.; Taslim, M.E.; Ghasemi, O.; Rezvani, S.; Borzooeian, G.; Nourbakhsh, A. A high precision method for length-based separation of carbon nanotubes using bio-conjugation, SDS-PAGE and silver staining. PLoS ONE 2018, 13, e0197972. [CrossRef] 
51. Abd-Elghany, M.; Klapötke, T.M. A review on differential scanning calorimetry technique and its importance in the field of energetic materials. Phys. Sci. Rev. 2018, 3. [CrossRef]

52. Ahmad, N.; Ahmad, R.; Al-Qudaihi, A.; Alaseel, S.E.; Fita, I.Z.; Khalid, M.S.; Pottoo, F.H. Preparation of a novel curcumin nanoemulsion by ultrasonication and its comparative effects in wound healing and the treatment of inflammation. RSC Adv. 2019, 9, 20192-20206. [CrossRef]

53. Gao, M.; Mei, D.; Huo, Y.; Mao, S. Effect of polysorbate 80 on the intranasal absorption and brain distribution of tetramethylpyrazine phosphate in rats. Drug Deliv. Transl. Res. 2019, 9, 311-318. [CrossRef] [PubMed]

54. Subongkot, T.; Ngawhirunpat, T. Development of a novel microemulsion for oral absorption enhancement of all-trans retinoic acid. Int. J. Nanomed. 2017, 12, 5585. [CrossRef] [PubMed]

55. Dua, R.; Zia, H.; Needham, T. The influence of tonicity and viscosity on the intranasal absorption of salmon calcitonin in rabbits. Int. J. Pharm. 1997, 147, 233-242. [CrossRef]

56. Espinoza, L.C.; Vacacela, M.; Clares, B.; Garcia, M.L.; Fabrega, M.-J.; Calpena, A.C. Development of a nasal donepezil-loaded microemulsion for the treatment of Alzheimer's disease: In vitro and ex vivo characterization. CNS Neurol. Disord. -Drug Targets (Former. Curr. Drug Targets-CNS Neurol. Disord.) 2018, 17, 43-53. [CrossRef]

57. Patel, M.R.; Patel, M.H.; Patel, R.B. Preparation and in vitro/ex vivo evaluation of nanoemulsion for transnasal delivery of paliperidone. Appl. Nanosci. 2016, 6, 1095-1104. [CrossRef]

58. Lin, H.; Gebhardt, M.; Bian, S.; Kwon, K.A.; Shim, C.-K.; Chung, S.-J.; Kim, D.-D. Enhancing effect of surfactants on fexofenadine$\mathrm{HCl}$ transport across the human nasal epithelial cell monolayer. Int. J. Pharm. 2007, 330, 23-31. [CrossRef]

59. Gharbavi, M.; Sharafi, A.; Motamed Fath, P.; Oruji, S.; Pakzad, H.; Kheiri Manjili, H. Formulation and biocompatibility of microemulsion-based pmbn as an efficient system for paclitaxel delivery. J. Appl. Biotechnol. Rep. 2021, 8. [CrossRef]

60. Shinde, U.; Pokharkar, S.; Modani, S. Design and evaluation of microemulsion gel system of nadifloxacin. Indian J. Pharm. Sci. 2012, 74, 237. [CrossRef]

61. Danaei, M.; Dehghankhold, M.; Ataei, S.; Hasanzadeh Davarani, F.; Javanmard, R.; Dokhani, A.; Khorasani, S.; Mozafari, M. Impact of particle size and polydispersity index on the clinical applications of lipidic nanocarrier systems. Pharmaceutics 2018, 10, 57. [CrossRef]

62. Zhang, Y.-T.; Wang, Z.; Shen, L.-N.; Li, Y.-Y.; He, Z.-H.; Xia, Q.; Feng, N.-P. A novel microemulsion-based isotonic perfusate modulated by Ringer's solution for improved microdialysis recovery of liposoluble substances. J. Nanobiotechnol. 2018, 16, 91. [CrossRef]

63. Sabale, V.; Vora, S. Formulation and evaluation of microemulsion-based hydrogel for topical delivery. Int. J. Pharm. Investig. 2012, 2, 140. [CrossRef] [PubMed]

64. Patel, V.; Kukadiya, H.; Mashru, R.; Surti, N.; Mandal, S. Development of microemulsion for solubility enhancement of clopidogrel. Iran. J. Pharm. Res. IJPR 2010, 9, 327.

65. Ontao, N.; Athikomkulchai, S.; Tadtong, S.; Leesawat, P.; Chittasupho, C. Formulation, Physical and Chemical Stability of Ocimum gratissimum L. Leaf Oil Nanoemulsion. In Proceedings of Key Engineering Materials; Trans Tech Publications Ltd.: Freienbach, Switzerland; pp. 117-122.

66. Rahdar, A.; Hajinezhad, M.R.; Sargazi, S.; Zaboli, M.; Barani, M.; Baino, F.; Bilal, M.; Sanchooli, E. Biochemical, Ameliorative and Cytotoxic Effects of Newly Synthesized Curcumin Microemulsions: Evidence from In Vitro and In Vivo Studies. Nanomaterials 2021, 11, 817. [CrossRef] [PubMed]

67. Kumar, M.; Pathak, K.; Misra, A. Formulation and characterization of nanoemulsion-based drug delivery system of risperidone. Drug Dev. Ind. Pharm. 2009, 35, 387-395. [CrossRef] [PubMed] 